\title{
Application of Image Analysis in Studies of Quantitative Disease Resistance, Exemplified Using Common Bacterial Blight-Common Bean Pathosystem
}

\author{
Weilong Xie, Kangfu Yu, K. Peter Pauls, and Alireza Navabi
}

All authors: Agriculture and Agri-Food Canada/University of Guelph Bean Breeding Program, c/o Department of Plant Agriculture, Crop Science Building, University of Guelph, 50 Stone Road, Guelph, ON, N1G 2W1, Canada; first, third, and fourth authors: Department of Plant Agriculture, University of Guelph, Canada; and first, second, and fourth authors: Greenhouse and Processing Crops Research Centre, Agriculture and Agri-Food Canada, 2585 County Road 20, Harrow, ON, N0R 1G0, Canada. Accepted for publication 21 December 2011.

\begin{abstract}
Xie, W., Yu, K., Pauls, K. P., and Navabi, A. 2012. Application of image analysis in studies of quantitative disease resistance, exemplified using common bacterial blight-common bean pathosystem. Phytopathology $102: 434-442$.

The effectiveness of image analysis (IA) compared with an ordinal visual scale, for quantitative measurement of disease severity, its application in quantitative genetic studies, and its effect on the estimates of genetic parameters were investigated. Studies were performed using eight backcross-derived families of common bean (Phaseolus vulgaris) $(n=172)$ segregating for the molecular marker SU91, known to be associated with a quantitative trait locus (QTL) for resistance to common

and $X$. fuscans subsp. fuscans. Even though both IA and visual assessments were highly repeatable, IA was more sensitive in detecting quantitative differences between bean genotypes. The CBB phenotypic difference between the two SU91 genotypic groups was consistently more than fivefold for IA assessments but generally only two- to threefold for visual assessments. Results suggest that the visual assessment results in overestimation of the effect of QTL in genetic studies. This may have been caused by lack of additivity and uneven intervals of the visual scale. Although visual assessment of disease severity is a useful tool for general selection in breeding programs, assessments using IA may be more suitable for phenotypic evaluations in quantitative genetic studies involving CBB resistance as well as other foliar diseases.
\end{abstract} bacterial blight (CBB), caused by Xanthomonas campestris pv. phaseoli
The agronomic importance of developing durably resistant cultivars has led to substantial research in the field of quantitative disease resistance (38). Quantitative disease resistance and its inheritance and mechanisms have been reported for many pathosystems (43). Mapping quantitative trait loci (QTL) has been a powerful tool for genetic dissection of quantitative traits, including disease resistance (43). Accurate, repeatable, reliable, and quantitative assessment of disease severity (phenotyping) is important for quantitative genetic studies $(5,21,32)$.

Visual assessment of disease severity for quantitative analyses, even though used in many studies, has raised concerns over its accuracy and precision (38). The use of visual rating scales for quantitative analyses has been criticized for being subjective and unrepeatable and for not providing an actual quantitative measure of disease severity, which may not be reliable for quantitative analyses (5,32). For example, QTL allele effects based on visual disease assessment for northern leaf blight resistance in maize were found highly variable and rater dependent (38).

Image analysis (IA) of infected plant tissue, on the other hand, has been reported to provide more objective, accurate, repeatable, and quantitative measure of disease severity (5), but there are also examples where IA has resulted in relatively poor disease assessments $(34,49)$. Newton (31) investigated the use of IA to screen

Corresponding author: A. Navabi; E-mail address: Alireza.Navabi@agr.gc.ca

* The $\boldsymbol{e}$-Xtra logo stands for "electronic extra" and indicates that Figure 1 appears in color online.

http://dx.doi.org/10.1094/PHYTO-06-11-0175

(c) 2012 The American Phytopathological Society barley germplasm with resistance to powdery mildew (Erisyphe graminis), and reported good correlations between disease severity and most components of partial resistance. IA was found to be more discerning than visual ratings in differentiating reactions of corn germplasm to Fusarium spp. causing stalk rot (48). Kokko et al. (18) used IA to measure total area and mean intensity of common root rot (Cochliobolus sativus) of barley and demonstrated that IA was sensitive to cultivar differences and was more objective and reliable than visual assessment. Bock et al. $(3,4)$ used IA to measure actual disease severity of citrus canker and found that IA was more reliable than visual rating.

Common bacterial blight (CBB), caused by Xanthomonas campestris pv. phaseoli and X. fuscans subsp. fuscans, is a damaging disease of common bean (Phaseolus vulgaris L.) throughout the world. Susceptible cultivars can suffer losses from CBB that, under severe infection, may exceed $40 \%$ of yield potential (40). The most effective and environmentally safe approach for controlling CBB is the use of resistant bean cultivars (42). Under moderate to severe disease pressure, the average yield advantage was $\leq 23 \%$ for moderately resistant cultivars (13). Resistance to $\mathrm{CBB}$ in common bean is known to be primarily inherited quantitatively $(10,25,26,41,45,56)$. At least 22 different QTL conditioning resistance to $\mathrm{CBB}$ have been identified across all 11 linkage groups of common bean in different studies (26). These QTL have been identified in common bean and closely related species, such as tepary bean (P. acutifolius L.) and scarlet runner bean ( $P$. coccineus L.), with $P$. acutifolius-derived resistance being most effective $(17,23,25,36,42,45,46)$. The identification of QTL and QTL-linked markers for CBB resistance facilitates pyramiding QTL from diverse sources to attain high levels of CBB resistance in bean breeding programs. However, different results concerning 
the role of specific QTL and interactions between QTL have been reported $(24,33,50,51)$.

Several visual rating methods have been used for CBB resistance. A commonly used rating scale ranges from 0 to $5(20,54$, 55 ) and is based on a visual estimate of the percentage of inoculated leaf area with disease symptoms $(0=$ no visible symptoms and $1=1$ to $10,2=11$ to $30,3=31$ to $50,4=51$ to 80 , and $5=$ $>80 \%$ area with symptoms). Yu et al. (56) introduced a 0-to-10 scale, based on visual estimate of the percentage of the diseased leaf area: $1=1$ to $4,2=5$ to $10,3=11$ to $20,4=21$ to $30,5=31$ to $40,6=41$ to $50,7=51$ to $60,8=61$ to $70,9=71$ to 85 , and $10=86$ to $100 \%$. A 1 -to- 9 scale (i.e., $1=$ no necrotic lesions or chlorosis and $2-3=1$ to $25.5,4$ to $6=26$ to 64.5 , and 7 to $9=65$ to $100 \%$ leaf area affected) was used $(1,50,51)$. Other researchers have used a 0 -to- $100 \%$ scale to visually estimate the percentage of inoculated area with disease symptoms $(2,16,29,30,35)$. There has not yet been a report of application of IA to study CBB resistance in common bean.

Among the several commercial IA programs currently available for measuring disease severity (5), the software Assess (19) has been successfully used for precise and accurate quantification of disease for several pathosystems $(3,4,7,14,15,47,52)$. In addition to the manual function, the newly released version of Assess (version 2.0) includes an automatic function that may provide fast and objective assessment of disease severity.

There is not enough information available on how disease assessments using IA compared with assessments using visual or ordinal scales may affect the estimates of parameters in markerQTL association studies. Hence, the objective of this study was to examine the application of IA compared with visual assessments in quantitative disease resistance studies, involving marker-QTL association studies, using CBB resistance in common bean as an example.

\section{MATERIALS AND METHODS}

Plant materials. Eight segregating backcross families from two generations, $F_{1}$ of first backcross $\left(\mathrm{BC}_{1} \mathrm{~F}_{1}\right)$ and $\mathrm{F}_{1}$ of second backcross $\left(\mathrm{BC}_{2} \mathrm{~F}_{1}\right)$, were used in this research (Table 1). Crosses were made by the Agriculture and Agri-Food Canada/University of Guelph Bean Breeding Program with the objective to pyramid CBB resistance QTL of different sources into a common background. The resistant parental lines ('MBE7', 'Rexeter', and 'Apex') were intercrossed in different combinations. The $\mathrm{F}_{1}$ progeny of the biparental crosses were then used in three-way crosses with a susceptible, but early-maturity commercial cultivar ('Nautica' or 'Ac Compass') followed by backcrosses to the susceptible parents to produce four $\mathrm{BC}_{1} \mathrm{~F}_{1}$ families (Table 1). Four $\mathrm{BC}_{2} \mathrm{~F}_{1}$ families were then derived from the second backcross of resistant $\mathrm{BC}_{1} \mathrm{~F}_{1}$ progeny with the susceptible genotypes ('Nautica' or 'AC Compass'). The resistant $\mathrm{BC}_{1} \mathrm{~F}_{1}$ progeny were identified by visual rating of disease severity performed 18 days after inoculation with $\mathrm{CBB}$ pathogens and genotyping with the previously known CBB-associated molecular marker SU91 $(27,37)$ as described below.

Growth room conditions. From each $\mathrm{BC}_{1} \mathrm{~F}_{1}$ and $\mathrm{BC}_{2} \mathrm{~F}_{1}$ family, 21 and 22 single plants, respectively, were planted in $15-\mathrm{cm}$ pots filled with Growing Mix (Lameque, New Brunswick, Canada) in a growth room at the Department of Plant Agriculture, University of Guelph in Guelph, Ontario, Canada. The temperature was set at 25 and $22^{\circ} \mathrm{C}$ day and night, respectively, with a 16-h photoperiod under a light intensity of $150 \mu \mathrm{mol} / \mathrm{m}^{2} / \mathrm{s}$. Pots were irrigated with an automatic irrigation system to maintain optimum soil moisture and were fertilized with 20-20-20 (N-P-K) once a week.

Pathogen inoculation. Artificial inoculation was performed 10 days after planting when the unifoliolates were fully expanded following the multiple needle method described by Yu et al. (54). To produce inoculum, two strains of $X$. campestris pv. phaseoli (numbers 18 and 98) and two strains of $X$. fuscans subsp. fuscans (numbers 12 and 118) collected in Ontario, Canada $(36,54)$ were grown on a yeast salt-agar plate (9) for $48 \mathrm{~h}$ at $25^{\circ} \mathrm{C}$. A suspension of the bacterial culture in distilled water was prepared for each strain with a concentration of $10^{8} \mathrm{CFU} / \mathrm{ml}$ and mixed, with an equal proportion from each strain. Inoculated plants were kept at $28^{\circ} \mathrm{C}$ for $16 \mathrm{~h}$ of light and $22^{\circ} \mathrm{C}$ for $8 \mathrm{~h}$ of night at a relative humidity of $90 \%$. Both unifoliolates of each of $84 \mathrm{BC}_{1} \mathrm{~F}_{1}$ and 88 $\mathrm{BC}_{2} \mathrm{~F}_{1}$ plants were inoculated in 2009 and 2010, respectively. Four plants of each parental line were inoculated and included in each test as positive checks.

Visual rating. At $\approx 14$ to 18 days after inoculation, when symptoms of susceptible cultivars were fully developed, visual assessment was performed by three individuals. These three individuals had experience with CBB disease and were pretrained with representative pictures of a 0 -to-5 visual scale (54). Unifoliolate leaves of the parental lines, $\mathrm{BC}_{1}$, and $\mathrm{BC}_{2}$ families were rated independently using the 0 -to-5 visual scale (54), which is based on the percentage of inoculated part of the leaf area with disease symptoms $(0=$ no visible symptoms and $1=1$ to $10,2=$ 11 to $30,3=31$ to $50,4=51$ to 80 , and $5=>80 \%$ are with symptoms). In total, 384 leaves (168 leaves of four $\mathrm{BC}_{1} \mathrm{~F}_{1}$ families, 176 leaves of four $\mathrm{BC}_{2} \mathrm{~F}_{1}$ families, and 40 leaves of parental lines) were assessed.

IA. Immediately after visual rating, the inoculated unifoliolate leaves were detached and placed horizontally on a piece of lightblue paper on a bench in the growth room. A digital image was then taken of the two leaves of each plant using a digital camera (Canon EOS Rebel T1i; Canon Inc., Taiwan) that was fixed on a tripod, $50 \mathrm{~cm}$ from the object. Digital images were saved as JPEG files. Analyses of images of CBB-affected leaves were performed using the software Assess 2.0 (The American Phytopathological Society, St. Paul, MN). Leaves with insect damage, which were observed rarely, were not included in the analysis. Both automatic and manual (classic) options of the software Assess 2.0 were used following the manufacturer's instructions. Some image enhancement (adjustment of contrast, brightness, and saturation) was used to optimize measurements when necessary, because of inconsistencies in lighting between images. In the automatic option of Assess 2.0, "\% Area" was selected to generate the percent diseased lesion area of one leaf (total lesion area/total leaf area), which included both chlorotic and necrotic areas of that leaf. The automatic option did not allow the separate measurements of chlorotic and necrotic areas to be made. In contrast, using the manual IA enabled data to be collected for percent lesion area as well as percent chlorotic area and percent necrotic area for each leaf. This

TABLE 1. Parentage of the segregating families inoculated with Xanthomonas campestris pv. phaseoli and X. fuscans subsp. fuscans and rated for disease severity using a visual rating and with image analyses techniques

\begin{tabular}{llc}
\hline Generation, families & \multicolumn{1}{c}{ Parentage $^{\mathrm{a}}$} & $\begin{array}{c}\text { Number of } \\
\text { plants }\end{array}$ \\
\hline $\mathrm{BC}_{1} \mathrm{~F}_{1}$ & & \\
1 & Nautica*2//Apex/MBE7 & 21 \\
2 & Nautica*2//Rexeter/Apex & 21 \\
3 & AC Compass*2//Apex/MBE7 & 21 \\
4 & AC Compass*2//Rexeter/Apex & 21 \\
$\mathrm{BC}_{2} \mathrm{~F}_{1}$ & Nautica*3//Apex/MBE7 & 22 \\
5 & Nautica*3//Rexeter/Apex & 22 \\
6 & AC Compass*3//Apex/MBE7 & 22 \\
7 & AC Compass*3//Rexeter/Apex & 22 \\
8 &
\end{tabular}

a Resistant parental lines ('MBE7', 'Rexeter', and 'Apex') were intercrossed in different combinations. The $\mathrm{F}_{1}$ progeny of the biparental crosses were then used in three-way crosses with a susceptible but early-maturity commercial cultivar ('Nautica' or 'AC Compass') followed by backcrosses to the susceptible parents to develop four $\mathrm{BC}_{1} \mathrm{~F}_{1}$ families. Four $\mathrm{BC}_{2} \mathrm{~F}_{1}$ families were then derived from the second backcross of resistant $\mathrm{BC}_{1} \mathrm{~F}_{1}$ progeny with the susceptible genotypes (Nautica or AC Compass). 
was done using "Classic panel" of the software, as explained in the user guide, by adjusting the threshold until the best coverage of the total lesion area or chlorotic area was selected based on operator's judgment, and then quantified (Fig. 1). The necrotic area was then calculated as total lesion area minus the chlorotic area. For a preliminary test, automatic IA was used by two different individuals (automatic IA1 and -2) to quantify 168 leaves of four $\mathrm{BC}_{1} \mathrm{~F}_{1}$ families. Because the correlation coefficient between the automatic IA1 and automatic IA2 assessments was $>0.99$ (Table 2), automatic IA2 was not used to assess $\mathrm{BC}_{2} \mathrm{~F}_{1}$ families. Assessments performed by automatic IA1 were used for all data analysis and for comparisons with other parameters. For each of the 344 leaves of eight families and their parental lines, percent lesion area was quantified by automatic IA and manual IA. In addition, percent chlorotic area and percent necrotic area of each leaf were quantified using manual IA.

Genomic DNA isolation and genotyping. Genomic DNA was isolated from young leaves of each plant according to the procedure described by $\mathrm{Yu}$ et al. (53). Each plant was genotyped with the previously known CBB-associated sequence-characterized amplified region (SCAR) marker SU91 $(27,37)$. SU91 is polymorphic between the resistant and susceptible parental lines and, therefore, segregating in the backcross families. Forward primer SU91-F (5'-CCACATCGGTTAACATGAGT) and reverse primer SU91-R (5'-CCACATCGGTGTCAACGTGA) were paired to polymerase chain reaction (PCR) amplify a 700-bp DNA fragment. The PCR amplifications were performed in 96-well plates in a MyCycler Thermal Cycler (Bio-Rad, Hercules, CA). The
PCR protocol for amplification of the SU91 was as described by Pedraza et al. (27), including 34 cycles of $10 \mathrm{~s}$ at $94^{\circ} \mathrm{C}, 40 \mathrm{~s}$ at $58^{\circ} \mathrm{C}$, and $120 \mathrm{~s}$ at $72^{\circ} \mathrm{C}$; followed by 1 cycle of $5 \mathrm{~min}$ at $72^{\circ} \mathrm{C}$. The PCR products were electrophoresed through $1.0 \%$ agarose containing ethidium bromide for $1 \mathrm{~h}$ at $100 \mathrm{~V}$.

Data analysis. Statistical analyses were performed using SAS (version 9.2; SAS Institute Inc., Cary, NC). Visual ratings by the three individuals and the IA estimates, separately for each generation, were subjected to analysis of variance using the PROC MIXED procedure, first separately for each family, with each inoculated leaf of a single plant as a random replication effect and individual plant as fixed effect. A second mixed-model analysis was then performed with family as fixed effect and replication and plant nested within family as random effects. Least square means (lsmeans) and standard error of lsmeans were computed for each individual in each family using LSMEANS and PDIFF statements in PROC MIXED. Correlation analyses were performed on the estimates of lsmeans for each parameter in each generation using the PROC CORR procedure to compute Pearson's correlation coefficients $\left(r_{p}\right)$ for the correlations among IA parameters. Moreover, Spearman's correlation coefficients $\left(r_{s}\right)$ were computed to study correlations with the ordinal scale. Regression analyses were performed using the PROC REG procedure, separately for each generation and for automatic IA and manual IA, with visual rating and IA parameters as dependent and independent variables, respectively. The visual ratings by the three individuals were highly correlated and, therefore, the ratings by one of the three raters were used in regression analyses. For each
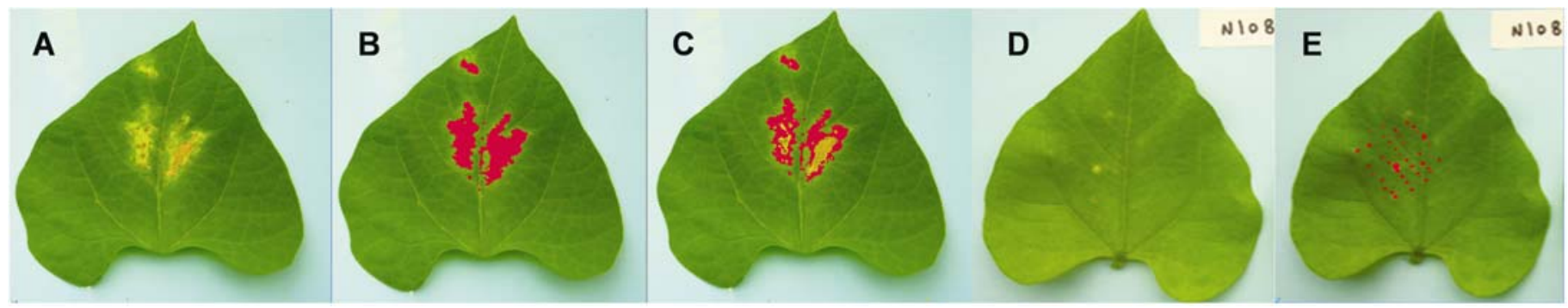

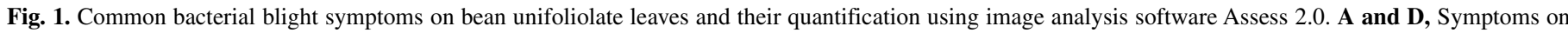

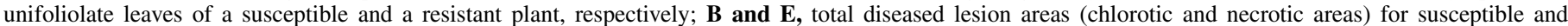

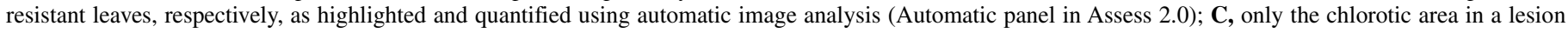
of a susceptible leaf as highlighted and quantified using manual image analysis (Classic panel in Assess 2.0).

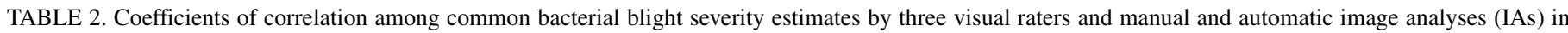
backcross-derived families ${ }^{\mathrm{a}}$

\begin{tabular}{|c|c|c|c|c|c|c|c|}
\hline \multirow[b]{2}{*}{ Generation, variable } & \multicolumn{5}{|c|}{$\mathrm{IA}^{\mathrm{b}}$} & \multicolumn{2}{|c|}{ Visual rating } \\
\hline & Auto-IA1 & Auto-IA2 & Manual-IA & Manual-Chl & Manual-Nec & Visual-1 & Visual-2 \\
\hline \multicolumn{8}{|l|}{$\mathrm{BC}_{1} \mathrm{~F}_{1}$} \\
\hline Auto-IA2 & 0.99 & $\ldots$ & $\ldots$ & $\ldots$ & $\ldots$ & $\ldots$ & $\ldots$ \\
\hline Manual-IA & 0.95 & 0.96 & $\ldots$ & $\ldots$ & $\ldots$ & $\ldots$ & $\ldots$ \\
\hline Manual-Chl & 0.93 & 0.94 & 0.97 & $\ldots$ & $\ldots$ & $\ldots$ & $\ldots$ \\
\hline Manual-Nec & 0.75 & 0.75 & 0.77 & 0.64 & $\ldots$ & $\ldots$ & $\ldots$ \\
\hline Visual-1 & 0.88 & 0.90 & 0.94 & 0.91 & 0.83 & $\ldots$ & $\ldots$ \\
\hline Visual-2 & 0.93 & 0.94 & 0.95 & 0.92 & 0.81 & 0.93 & $\ldots$ \\
\hline Visual-3 & 0.87 & 0.87 & 0.90 & 0.87 & 0.73 & 0.88 & 0.93 \\
\hline \multicolumn{8}{|l|}{$\mathrm{BC}_{2} \mathrm{~F}_{1}$} \\
\hline Manual-IA & 0.96 & - & $\ldots$ & $\ldots$ & $\ldots$ & $\ldots$ & $\ldots$ \\
\hline Manual-Chl & 0.92 & - & 0.97 & $\ldots$ & $\ldots$ & $\ldots$ & $\ldots$ \\
\hline Manual-Nec & 0.79 & - & 0.80 & 0.62 & $\ldots$ & $\ldots$ & $\ldots$ \\
\hline Visual-1 & 0.90 & - & 0.93 & 0.92 & 0.82 & $\ldots$ & $\ldots$ \\
\hline Visual-2 & 0.90 & - & 0.92 & 0.89 & 0.85 & 0.95 & $\ldots$ \\
\hline Visual-3 & 0.85 & - & 0.87 & 0.84 & 0.77 & 0.89 & 0.90 \\
\hline
\end{tabular}

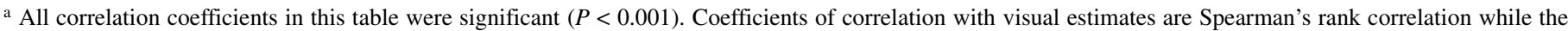
other coefficients are Pearson's coefficient of correlation.

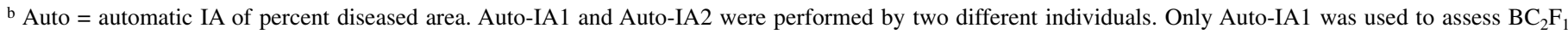
because Auto-IA1 and Auto-IA2 were highly correlated $\left(r_{p}=0.99\right)$. Manual-IA, -Chl, and $-\mathrm{Nec}=$ manual IA of percent diseased area, chlorotic area, and necrotic area, respectively. 
relationship, linear and logarithmic regression lines were predicted and the coefficient of determination $\left(R^{2}\right)$ was computed as a measure of the proportion of variance accounted for by each regression model. Moreover, Akaike's Information Criterion (AIC), Bayes's Information Criterion (BIC), Mallows's $C_{p}$ statistic, and the mean square of error for each regression model were computed in SAS PROC REG procedure as criteria for selecting the best regression model.

For each family and then for each generation, the associations between the presence or absence of the SU91 marker with phenotypic values for the visual and image analyses parameters were examined using single-marker QTL analyses with a linear model, using PROC GLM, in which the CBB phenotypic value (either from the visual rating or IA) was the dependent variable and the marker genotype was the independent variable. For each analysis, the coefficient of determination $\left(R_{p}^{2}\right)$ was computed as a measure of the proportion of phenotypic variance accounted for by the QTL associated with SU91. The lsmeans value of each marker genotype was estimated in each family and in each generation and the additive effect of the locus was estimated as half of the difference between the lsmeans values of the two genotypic groups (11). For each parameter, a differentiation ratio was estimated as the ratio of lsmeans values of the two SU91 genotypic groups.

\section{RESULTS}

Disease symptoms and severity. Although only necrotic dots appeared in the inoculation sites in highly resistant plants, irregularly shaped necrotic spots bordered by lemon-yellow rings developed on the unifoliolates of the susceptible plants 14 to 18 days after inoculation. On leaves of some susceptible plants, lesions expanded to uninoculated areas (Fig. 1). The three resistant parental lines 'MBE7', 'Rexeter', and 'Apex' had 0.22, 0.28, and $0.29 \%$ lesion area, respectively, in manual IA assessments. Particularly, the resistant parental lines in manual IA assessments showed no or low portion of chlorosis (Table 3). Susceptible 'Nautica' and 'AC Compass' had 6.03 and $4.55 \%$ lesion area, respectively, in manual IA assessments. On these cultivars, in contrast to resistant parental lines, disease severity measured by manual IA indicated a higher proportion of chlorotic than necrotic lesion. For example, 'Nautica' had $5.41 \%$ chlorosis and $0.62 \%$ necrosis, and 'Ac Compass' had $3.80 \%$ chlorosis and $0.75 \%$ necrosis, compared with $0 \%$ chlorosis and $0.28 \%$ necrosis for the resistant parent 'Rexeter', and $0.14 \%$ chlorosis and $0.15 \%$ necrosis for moderate resistant parent 'Apex'. In visual assessments, the three raters, on average, scored 'Rexeter' as 0 but scored 'MBE7' as 0 to 0.25 and 'Apex' as 0.25 to 0.88 . Disease severity of the susceptible checks 'Nautica' and 'Ac Compass', rated by the three raters, was 3.25 to 4.38 and 3.25 to 4.00 , respectively.

Disease severity (percent lesion area) for $\mathrm{BC}_{1} \mathrm{~F}_{1}$, estimated by automatic IA and manual IA, was 0.25 to 25.72 and 0.04 to $31.99 \%$, respectively. Disease severity measured for $\mathrm{BC}_{2} \mathrm{~F}_{1}$ had similar ranges, 0.12 to $21.76 \%$ with automatic IA and 0.08 to $28.57 \%$ with manual IA. The maximum disease severities for both $\mathrm{BC}_{1}$ and $\mathrm{BC}_{2}$ generations were higher than for the susceptible parental lines (Table 3), indicating the presence of transgressive segregation for CBB response in the families. As in the susceptible parental lines, on average chlorotic area was the main contributor to total lesion area in both $\mathrm{BC}_{1}$ and $\mathrm{BC}_{2}$ generations. Disease severity of $\mathrm{BC}_{1} \mathrm{~F}_{1}$ and $\mathrm{BC}_{2} \mathrm{~F}_{1}$ estimated by three visual raters was 0 to 4.5 or 0 to 5 , respectively (Table 3 ). Because there are only scores 0 to 5 in visual rating, the transgressive segregation in $\mathrm{BC}_{1}$ and $\mathrm{BC}_{2}$ was not as apparent with visual assessments as it was with IA assessments (Table 3).

TABLE 3. Mean, standard deviation (Std), median, minimum (Min) and maximum (Max) for common bacterial blight severity estimates for parental lines and backcross (BC) progeny of different crosses, by three visual raters and by using manual and automatic image analysis (IA)

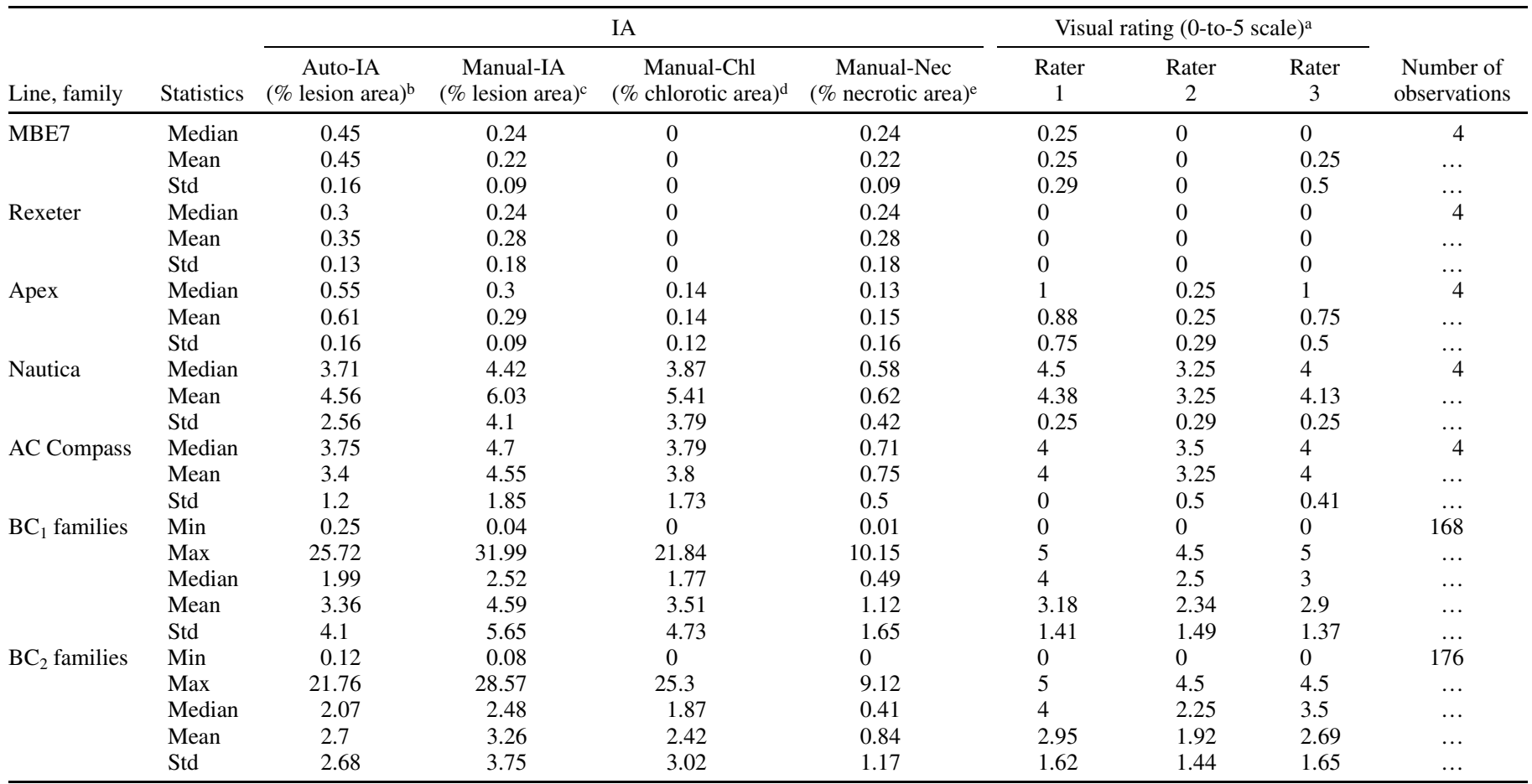

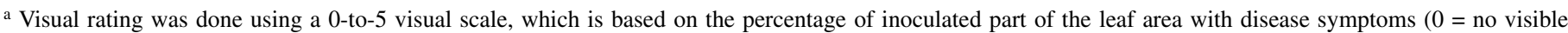
symptoms and $1=1$ to $10,2=11$ to $30,3=31$ to $50,4=51$ to 80 , and $5=>80 \%$ area with symptoms).

b Automatic IA of diseased area.

c Manual IA of diseased area.

d Manual IA of percent chlorotic area.

e Manual IA of percent necrotic area. 
Repeatability of assessments in IA and visual rating. When automatic IA was used by two different individuals to quantify 168 leaves of four $\mathrm{BC}_{1} \mathrm{~F}_{1}$ families, the correlation coefficient between the two assessments was $r_{p}=0.99$ (Table 2). Automatic IA and manual IA values were highly correlated with correlation coefficients of $r_{p}>0.95(P<0.001)$ in both $\mathrm{BC}_{1}$ and $\mathrm{BC}_{2}$ populations (Table 2). For the $\mathrm{CBB}$ disease symptoms measured in this study, disease severity (total lesion area) was more strongly correlated with chlorotic area $\left(r_{p}=0.97\right)$ than necrotic area $\left(r_{p}=0.77\right)$ (Table 2).

Visual assessments were highly correlated among raters, with correlation coefficients of $r_{s}=0.88$ to $0.93(P<0.001)$ in the $\mathrm{BC}_{1}$ generation and $r_{s}=0.89$ to $0.95(P<0.001)$ in the $\mathrm{BC}_{2}$ generation for three independent visual assessments (Table 2). IA (both automatic IA and manual IA) also showed high correlation with visual assessments, with correlation coefficients of 0.85 to 0.95 in two generations.

Visual rating had a positive but nonlinear association with IA (both automatic IA and manual IA) in both $\mathrm{BC}_{1}$ and $\mathrm{BC}_{2}$ generations (Fig. 2). In all cases, with increased diseased area in IA, the visual estimates reached a plateau when diseased area reached 5 to $10 \%$, indicating that visual estimates with this ordinal scale did not differentiate disease well at higher disease severities. Logarithmic regression models provided a better fit to the data compared with linear models, with $R^{2}$ values of 0.7 to 0.9 compared with 0.4 to 0.5 for linear models. Moreover, the values of $\mathrm{AIC}, \mathrm{BIC}$, and the mean square of the error for logarithmic regressions were always smaller than those calculated for linear regressions, indicating a nonlinear relation of IA estimates and visual scores. Manual IA assessments always had higher $R^{2}$ values in logarithmic regression with visual assessments $\left(R^{2}=0.90\right.$ for both $\mathrm{BC}_{1}$ and $\mathrm{BC}_{2}$ generations) than with automatic IA assessments $\left(R^{2}=0.71\right.$ for both $\mathrm{BC}_{1}$ and $\mathrm{BC}_{2}$ generations $)$.

In general, IA and visual assessments corresponded more closely in low disease severities than in high disease severities. With visual disease severity estimates in the 4 to 5 range, the IA values in $\mathrm{BC}_{1}$ varied from 0.5 to $18.6 \%$ for automatic IA and from 2.4 to $21.9 \%$ for manual IA. A similar pattern was also observed for $\mathrm{BC}_{2}$, at 1.6 to $12.4 \%$ for automatic IA and 3.0 to $16.3 \%$ for manual IA. These results indicated that IA assessment differentiates better than visual estimates, especially in severe disease situations. The high differentiation ability of IA was shown by both automatic and manual analysis approaches in both $\mathrm{BC}_{1}$ and $\mathrm{BC}_{2}$ generations (Fig. 2).

Association of disease severity with CBB-linked SCAR marker SU91. The association of each one of the visual or IA parameters with the CBB-linked SCAR marker SU91 was used to examine the potential of IA in CBB-resistance genetic studies. The difference in disease severity between SU91-absent and SU91-present genotypes was always significant $(P<0.001)$ (Table 4). Without exception, SU91 was associated $(P<0.001)$ with $\mathrm{CBB}$ severity in all eight families in both $\mathrm{BC}_{1}$ and $\mathrm{BC}_{2}$ generations. However, IA provided greater differentiation between the two SU91 genotypic groups (Table 4). In the $\mathrm{BC}_{1}$ generation, the difference between the two SU91 genotypic groups was 5.5to 21.0-fold for IA assessments but only 2.2- to 3.1-fold for visual assessments. In IA assessments, manual IA with differentiation ratio of 11.0 had twice the differentiation ratio of automatic IA (5.5). For the symptom components measured by manual IA, percent chlorotic area had a higher differentiation ratio than percent necrotic area. In the $\mathrm{BC}_{2}$ generation, the differentiation ratios for different IA parameters followed the same pattern as $\mathrm{BC}_{1}$, ranging from 6.2 to 16.2 , with percent chlorotic area providing the highest differentiation among the two genotypic groups.

There was high variation among three different visual raters in $\mathrm{BC}_{2}$ for differentiation among the two SU91 genotypic groups, ranging from 3.5 to 9.6. Moreover, there were inconsistencies between visual ratings of the same individuals for $\mathrm{BC}_{1}$ and $\mathrm{BC}_{2}$ families. Between $\mathrm{BC}_{1}$ and $\mathrm{BC}_{2}$ generations, rater 1 had relatively consistent differentiation ratios (2.2 and 3.5 , respectively), but rater 2 had a differentiation ratio of 3.1 for $\mathrm{BC}_{1}$ and 9.6 for $\mathrm{BC}_{2}$. Similarly, rater 3 had a differentiation ratio of 2.2 for $\mathrm{BC}_{1}$ and 5.5
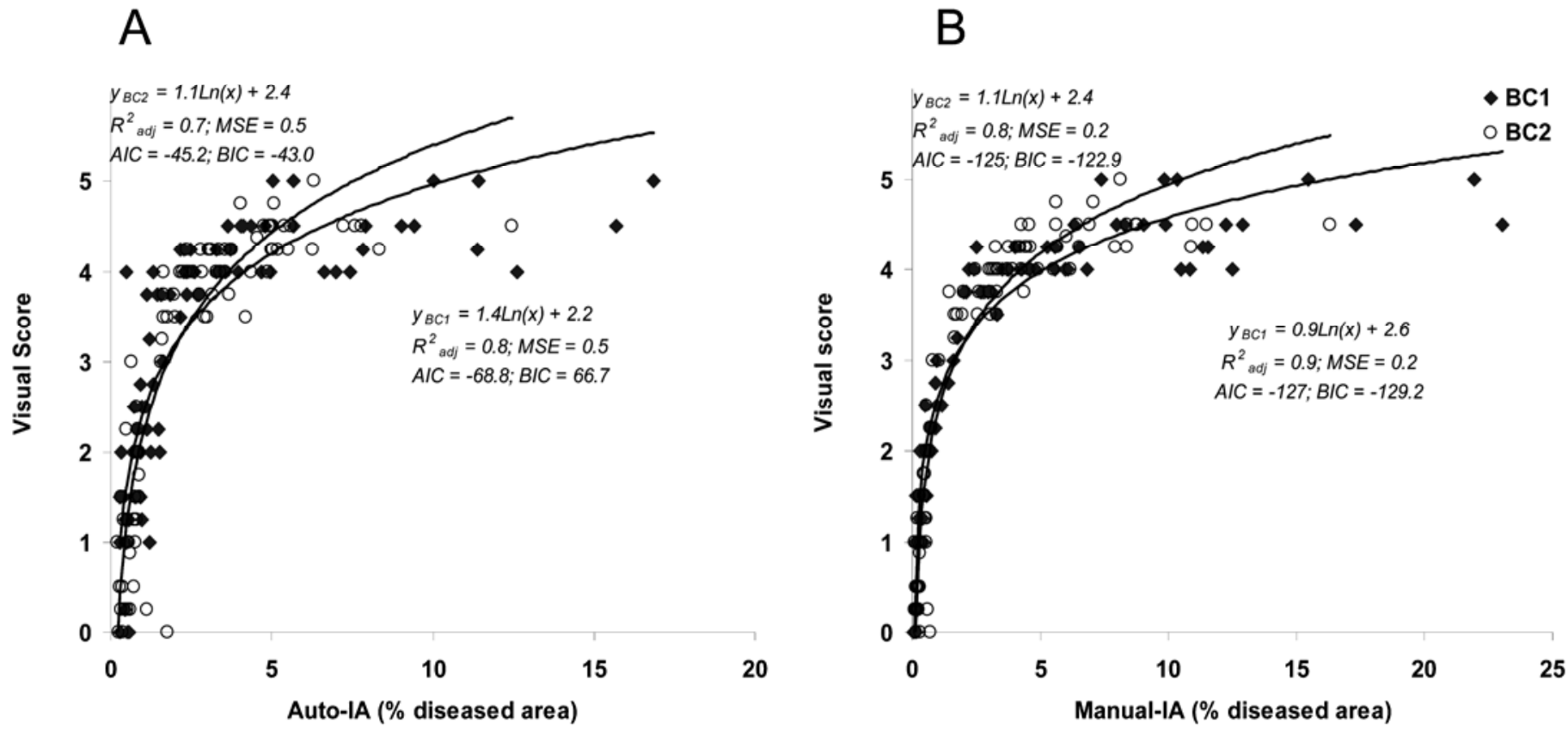

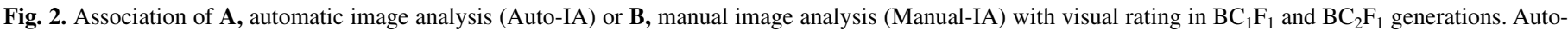

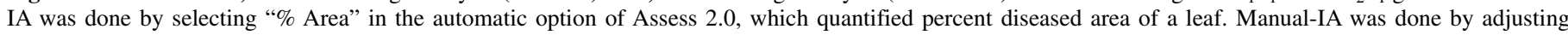

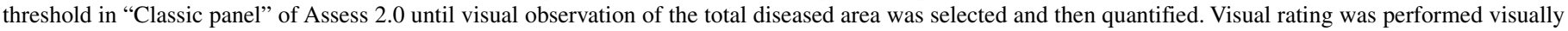

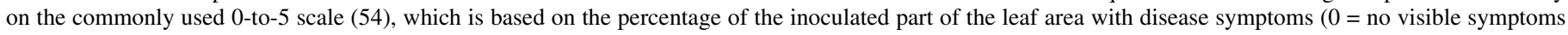

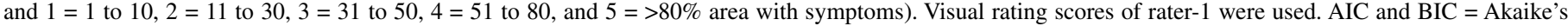

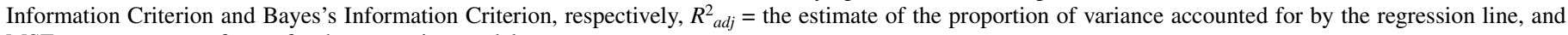
$\mathrm{MSE}=$ mean square of error for the regression model. 
for $\mathrm{BC}_{2}$. In contrast, the differentiation ratios were more consistent for each IA parameter between $\mathrm{BC}_{1}$ and $\mathrm{BC}_{2}$ generations (Table 4), demonstrating a higher level of reliability of IA assessments.

The proportion of the $\mathrm{CBB}$ phenotypic variance accounted for by the marker SU91 was 64 to $75 \%$ for $\mathrm{BC}_{1}$ and 74 to $88 \%$ for $\mathrm{BC}_{2}$ families for visual assessments but only 31 to $39 \%$ for $\mathrm{BC}_{1}$ and 42 to $43 \%$ for $\mathrm{BC}_{2}$ assessment using IA based on percent lesion area by automatic IA or manual IA. Generally, the $R_{p}^{2}$ values were consistent between different families in IA assessments. However, in some families (e.g., 2 and 7 in Table 4), the $R_{p}^{2}$ values were higher than others (70 to $74 \%$ and 63 to $64 \%$, respectively). This might have been caused by small population sizes (21 and 22 plants, respectively). If considered as whole generations of $\mathrm{BC}_{1}$ (84 plants) and $\mathrm{BC}_{2}$ (88 plants), the proportion of the CBB resistance phenotypic variance for IA assessments accounted for by the marker SU91 was quite comparable at 31 to $39 \%$ for $\mathrm{BC}_{1}$ and 42 to $43 \%$ for $\mathrm{BC}_{2}$.

\section{DISCUSSION}

IA was shown to be a highly repeatable technique for assessing CBB symptom severity in common bean. When automatic IA was used by two different individuals to quantify 168 leaves of four $\mathrm{BC}_{1} \mathrm{~F}_{1}$ families, the correlation coefficient between the two assessments was $>0.99$. This is not surprising because the assessment procedures for automatic IA were done automatically and did not involve any judgment of operators. Also, automatic IA and manual IA showed high correlation $\left(r_{p}>0.95\right)$ that was reproducible in both $\mathrm{BC}_{1}$ and $\mathrm{BC}_{2}$ generations, which were inoculated in different years. These observations agree with conclusions from several previous studies $(3,6,12,21,39)$ regarding the high precision of IA. The visual ratings (0-to-5 scale) in this study were also shown to be repeatable for CBB disease assessments made while comparing different raters, with correlation coefficients of 0.88 to 0.95 for the two generations examined.

The current finding that IAs (both automatic IA and manual IA) had nonlinear associations with visual ratings (in both $\mathrm{BC}_{1}$ and $\mathrm{BC}_{2}$ generations) was not consistent with previous observations for citrus canker (3), where a linear relationship between IA estimates and visual estimates of disease was reported. The difference may be attributable to differences in the visual evaluations in the studies since Bock et al. (3) directly estimated disease sever- ity, expressed as percent area affected, whereas, in the current study, a 0-to-5 ordinal scale was used to assess disease severity. The nonlinear relationship between the visual and IA assessments suggests that the visual scale lacks additivity, which is caused by the intervals not being equal. Additivity of data is an assumption of most parametric statistical analyses, including any kind of analysis of variance (44).

This study demonstrated that IA provided a more objective quantification of CBB symptom severity in common bean. In contrast, methods currently employed for estimating CBB disease severity by breeders and pathologists are semiquantitative and involve the use of different rating scales based on visual estimates of disease severity $(1,2,16,20,28-30,35,50,51,54,55,58)$. Visual scales are subjective and only semiquantitative. For example, because there are only six categories $(0,1,2,3,4$, and 5$)$ in the 0 to-5 scale, each interval includes a range of disease severities. An interval from score 4 to 5 in visual ratings included different lesion areas of 2.4 to $21.9 \%\left(\mathrm{BC}_{1}\right)$ and 3.0 to $16.3 \%\left(\mathrm{BC}_{2}\right)$ measured by manual IA (Fig. 2). Some researchers have used more detailed scoring scales such as 1 to 9 or 0 to $100 \%$ to visually estimate the CBB disease severity $(1,50,51)$. However, these scales are not quantitative, either. Moreover, scales with too many categories tend to have more variations and may be less repeatable (5). It should be noted that the logarithmic regression lines with manual IA assessments usually had higher $R^{2}$ values than automatic IA assessments. This may be because manual IA requires a threshold to be defined by the operator. This involves visual judgment of the borders of the diseased area, a process that, to some extent, is similar to visual assessments. However, visual assessments estimate not only borders of diseased areas and nondiseased areas but also values of diseased areas. The latter causes substantial variations for visual assessments $(5,32)$. In contrast, both manual IA and automatic IA provide quantitative measurements for disease severities with higher precision.

This study also revealed the high differentiation power of IA. Although the differences in disease severity between SU91-absent and SU91-present genotypic groups were significant in all visual and IA assessments, the IA assessments provided higher differentiation between these two genotypic groups than the visual ratings. The differentiation ratios between the two genotypic groups were $>5$-fold for all IA parameters, with 21 -fold as the highest (percent chlorotic area). In contrast, visual assessments in most cases only provided two- to threefold differentiation ratios. This results support the previous observations that IA provides

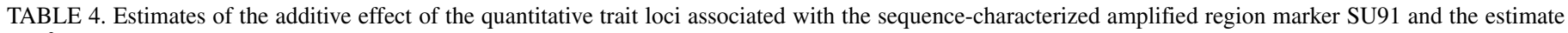
of $R_{p}^{2}$ for common bacterial blight severity estimates by three visual raters and by manual and automatic image analyses (IAs) ${ }^{\mathrm{a}}$

\begin{tabular}{|c|c|c|c|c|c|c|c|c|c|c|c|c|c|c|}
\hline \multirow[b]{3}{*}{ Generation, family ${ }^{b}$} & \multicolumn{8}{|c|}{$\mathrm{IA}^{\mathrm{c}}$} & \multicolumn{6}{|c|}{ Visual rating } \\
\hline & \multicolumn{2}{|c|}{ Auto-IA } & \multicolumn{2}{|c|}{ Manual-IA } & \multicolumn{2}{|c|}{ Manual-Chl } & \multicolumn{2}{|c|}{ Manual-Nec } & \multicolumn{2}{|c|}{ Visual-1 } & \multicolumn{2}{|c|}{ Visual-2 } & \multicolumn{2}{|c|}{ Visual-3 } \\
\hline & Add. & $R_{p}^{2}$ & Add. & $R_{p}^{2}$ & Add. & $R_{p}^{2}$ & Add. & $R_{p}^{2}$ & Add. & $R_{p}^{2}$ & Add. & $R_{p}^{2}$ & Add. & $R_{p}^{2}$ \\
\hline \multicolumn{15}{|l|}{$\mathrm{BC}_{1} \mathrm{~F}_{1}$} \\
\hline 1 & 2.0 & 0.4 & 3.2 & 0.5 & 2.3 & 0.4 & 0.9 & 0.5 & 0.9 & 0.8 & 1.1 & 0.7 & 0.9 & 0.7 \\
\hline 2 & 4.4 & 0.7 & 6.4 & 0.7 & 5.6 & 0.7 & 1.4 & 0.8 & 1.1 & 0.7 & 1.4 & 0.8 & 0.8 & 0.4 \\
\hline 3 & 1.3 & 0.4 & 2.3 & 0.5 & 2.0 & 0.4 & 0.3 & 0.2 & 1.0 & 0.9 & 1.0 & 0.6 & 1.0 & 0.8 \\
\hline 4 & 1.0 & 0.4 & 1.7 & 0.6 & 1.7 & 0.6 & 0.2 & 0.4 & 1.4 & 0.8 & 1.2 & 0.7 & 1.3 & 0.8 \\
\hline Overall & 2.1 & 0.3 & 3.3 & 0.4 & 2.7 & 0.4 & 0.6 & 0.3 & 1.1 & 0.8 & 1.2 & 0.7 & 1.0 & 0.6 \\
\hline Differentiation ratio & 5.5 & $\ldots$ & 11.0 & $\ldots$ & 21.0 & $\ldots$ & 5.5 & $\ldots$ & 2.2 & $\ldots$ & 3.1 & $\ldots$ & 2.2 & $\ldots$ \\
\hline \multicolumn{15}{|l|}{$\mathrm{BC}_{2} \mathrm{~F}_{1}$} \\
\hline 5 & 1.7 & 0.5 & 2.2 & 0.4 & 1.8 & 0.4 & 0.4 & 0.2 & 1.5 & 0.8 & 1.2 & 0.6 & 1.4 & 0.8 \\
\hline 6 & 1.4 & 0.4 & 2.0 & 0.4 & 1.6 & 0.5 & 0.4 & 0.1 & 1.7 & 0.9 & 1.2 & 0.7 & 1.7 & 0.9 \\
\hline 7 & 1.4 & 0.6 & 1.9 & 0.6 & 1.3 & 0.7 & 0.6 & 0.3 & 1.2 & 0.9 & 1.4 & 0.9 & 1.6 & 0.9 \\
\hline 8 & 1.8 & 0.4 & 2.8 & 0.4 & 2.0 & 0.4 & 0.7 & 0.4 & 1.4 & 0.9 & 1.3 & 0.8 & 1.6 & 0.9 \\
\hline Overall & 1.6 & 0.4 & 2.2 & 0.4 & 1.7 & 0.4 & 0.5 & 0.2 & 1.4 & 0.8 & 1.3 & 0.7 & 1.6 & 0.9 \\
\hline Differentiation ratio & 6.2 & $\ldots$ & 11.9 & $\ldots$ & 16.2 & $\ldots$ & 6.6 & $\ldots$ & 3.5 & $\ldots$ & 9.6 & $\ldots$ & 5.5 & $\ldots$ \\
\hline
\end{tabular}

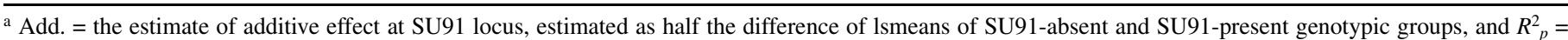
the estimate of the proportion of the phenotypic variance accounted for be the QTL associated with the marker SU91.

${ }^{\mathrm{b}}$ Differentiation ratio was estimated as the ratio of least square means of SU91-absent over SU91-present.

c Auto = automatic IA of percent diseased area; Manual-IA, -Chl, and -Nec = manual IA of percent diseased area, chlorotic area, and necrotic area, respectively. 
better differentiation and sensitivity than visual assessments $(21,22,48)$.

This study also suggests that IA data is more suitable for quantitative genetic studies and provides more reliable estimates of genetic effects. The CBB-associated marker SU91 was reported to account for $\approx 14 \%$ of the phenotypic variation in $\mathrm{CBB}$ resistance in an $F_{2}$ population derived from a cross between 'XAN 159' (resistant) and 'Chase' (moderately susceptible) (35), and for $17 \%$ of the phenotypic variation in a $\mathrm{BC}_{2} \mathrm{~F}_{1}$ population derived from crosses between XAN 159 and Chase, where Chase was used as the recurrent parent $(29,51)$. Those previous studies used a visual phenotyping method for estimating disease severity as a percent area affected, a different visual assessment from the 0 -to-5 scale used in this study. In the present study, the marker SU91 was found to account for 64 to $88 \%$ phenotypic variance using visual assessment based on a 0 -to- 5 scale but only 31 to $43 \%$ using IA (Table 4). This suggests that the visual assessment using an ordinal scale with few categories may result in overestimation of the actual effect of QTL. It is our opinion that this is due to the lack of additivity when disease severities are assessed visually using this 0-to-5 scale. Our experience in a QTL mapping study (Durham et al., unpublished) indicates that, even though estimates of the effect of the QTL are generally smaller with IA than with 0-to-5 scale visual rating, IA compared with visual assessments is more sensitive in detecting smaller effect QTL. The large variation in the estimates of SU91 effects derived from visual estimates in this study and previous studies $(29,35)$ is in agreement with a recent publication (38). Poland et al. (38) reported that the magnitudes of estimated allele effects by different raters at identified QTL for northern leaf blight resistance in maize varied drastically, emphasizing that care should be taken when estimating QTL allele effects based on visual disease assessments.

By using a new version of Assess (version 2.0), we were able to compare manual IA with automatic IA in CBB studies. The two approaches showed a high level of agreement in assessing total percent area with CBB lesions. Automatic IA provides a reasonably fast quantification of disease symptom severity, requiring only a single click to compute the total percent disease area for each sample. It generally takes no more than $1 \mathrm{~min}$ to assess one sample, including image enhancement, if required. IA automation is advantageous when assessing large numbers of samples. On the other hand, although the manual IA procedure is more timeconsuming ( $\approx 3 \mathrm{~min}$ for each sample), it allows nonlesion areas to be eliminated by only selecting inoculated areas. Importantly, it makes it possible to analyze the components of disease reaction by separately quantifying the percent chlorotic and percent necrotic areas. Different combinations of $\mathrm{CBB}$ pathogen strains and bean genotypes may have different symptoms or different ratios of percent chlorotic and percent necrotic areas (57). It will be an advantage to use manual IA to quantitatively evaluate the components for differential reactions of a set of common bean lines when inoculated with different $X$. campestris pv. phaseoli or $X$. fuscans subsp. fuscans strains. Therefore, both automatic IA and manual IA are potential tools for CBB quantification under greenhouse conditions, and the preference could be based on research goals, sample size, and symptom expression. IA is more time-consuming than visual ratings. IA does not have the ability to differentiate symptoms of the disease of interest from other diseases or insect-derived symptoms. In addition, it is not practically feasible to quantify CBB symptoms using IA in the field because of complicated background and other diseases or damages.

The ability to separately quantify chlorotic and necrotic areas of the lesion by IA revealed that the chlorotic response was the main reaction in susceptible genotypes and that there were differences between the genotypes in the amount of necrotic versus chlorotic areas. The highly resistant genotypes ('MBE7' and
'Rexeter') only showed necrosis. The lesions of $\mathrm{CBB}$ in the moderately resistant genotype, 'Apex', were composed of almost equals amount of chlorotic and necrotic areas, whereas the lesions of the susceptible genotypes ('Ac Compass' and 'Nautica') were mainly composed of chlorotic areas. Necrosis around inoculated sites in the resistant parental lines may have been caused by the mechanical damage of the needles. However, our unpublished results indicate that susceptible or resistant bean genotypes show no necrosis or chlorosis in response to inoculation with water. On the leaves of resistant genotypes, mechanical wounds appeared after inoculation with water but necrosis (sometimes with pigmentation) appeared after inoculation with CBB pathogens. The higher necrosis response in the resistant genotypes compared with susceptible genotypes may suggest an association between resistance to CBB and hypersensitive response mechanisms. Drijfhout and Blok (8) previously reported that resistance in $P$. acutifolius accession PI319443 was expressed as a hypersensitive response. Because both 'Apex' and 'Rexeter' have a resistance source from $P$. acutifolius accession PI319443, it is possible that the resistance in current populations was expressed as a hypersensitive response, too. This hypothesis, however, would require further molecular, biochemical, and histological investigation.

The methods used to estimate disease severity for genetic studies should ideally be simple, fast, flexible, quantitative, sensitive, accurate, and repeatable $(5,21)$. Visual rating is simple and flexible, and can distinguish $\mathrm{CBB}$ symptoms from other diseases and lesions caused by other factors. Our study verified that, for CBB in common bean, the repeatability among different visual raters is generally high but the resulting phenotypic differentiation and sensitivity of visual rating is not as high as IA. Visual assessment of CBB severity is still a useful tool for general selection in breeding programs, especially for screening large breeding populations. However, it is evident from results in this study that assessments using IA (manual IA or automatic IA) are more reliable and suitable for phenotypic evaluations in quantitative genetic studies for $\mathrm{CBB}$ resistance, avoiding underestimation or overestimation of genetic parameters. IA should be useful for QTL analysis of quantitative disease resistance in other pathosystems because of its sensitive detection ability and the quantitative nature of the measurements.

\section{ACKNOWLEDGMENTS}

The postdoctoral fellowship of W. Xie was supported by Agriculture and Agri-Food Canada through the NSERC Visiting Fellowship Program in the Canadian Government Laboratories. We thank P. Goodwin for his constructive suggestions and comments; T. Rupert, T. Smith, J. Brazolot, K. Durham, and S. McClymont for technical assistance; and the Ontario Bean Producers' Marketing Board (OBPMB), the Ontario Coloured Bean Growers' Association (OCBGA), and Agriculture and Agri-Food Canada for their financial support.

\section{LITERATURE CITED}

1. Aggour, A. R., Coyne, D. P., and Vidaver, A. K. 1989. Comparison of leaf and pod disease reactions of beans (Phaseolus vulgaris L.) inoculated by different methods with strains of Xanthomonas campestris pv. phaseoli (Smith) Dye. Euphytica 43:143-152.

2. Arnaud-Santana, E., Coyne, D. P., Eskridge, K. M., and Vidaver, A. K. 1994. Inheritance; low correlations of leaf, pod and seed reactions to common blight disease in common beans; and implications for selection. J. Am. Soc. Hortic. Sci. 119:116-121.

3. Bock, C. H., Parker, P. E., Cook, A. Z., and Gottwald, T. R. 2008. Visual rating and the use of image analysis for assessing different symptoms of citrus canker on grapefruit leaves. Plant Dis. 92:530-541.

4. Bock, C. H., Parker, P. E., Cook, A. Z., and Gottwald, T. R. 2009. Automated image analysis of the severity of foliar citrus canker symptoms. Plant Dis. 93:660-665.

5. Bock, C. H., Poole, G. H., Parker, P. E., and Gottwald, T. R. 2010. Plant disease severity estimated visually, by digital photography and 
image analysis, and by hyperspectral imaging. Crit. Rev. Plant Sci. 29:59107.

6. Díaz-Lago, J. E., Stuthman, D. D., and Leonard, K. J. 2003. Evaluation of components of partial resistance to oat crown rust using digital image analysis. Plant Dis. 87:667-674.

7. Donzelli, B. G. G., and Churchill., A. C. L. 2007. A quantitative assay using mycelial fragments to assess virulence of Mycosphaella fijiensis. Phytopathology 97:916-929.

8. Drijfhout, E., and Blok W. J. 1987. Inheritance of resistance to Xanthomonas campestris pv. phaseoli in tepary bean (Phaseolus acutifolius). Euphytica 36:803-808.

9. Dye, D. W. 1968. A taxonomic study of the genus Erwinia 1 'amylovora' group. N. Z. J. Sci. 11:590-607.

10. Eskridge, K. M., and Coyne, D. P. 1996. Estimating and testing hypothesis about the number of genes using inbred-backcross data. J. Hered. 87:410-412.

11. Falconer D. S. 1989. Introduction to Quantitative Genetics, 3rd ed. Longman, New York.

12. Garling, J., Rimelspach, R., and Boehm, M. J. 1999. A comparison of four methods to accurately measure dollar spot severity of turfgrass. (Abstr.) Phytopathology 89:S26.

13. Gillard, C. L., Conner, R. L., Howard, R. J., Pauls, K. P., Shaw, L., and Tar'an, B. 2009. The performance of dry bean cultivars with and without common bacterial blight resistance in field studies across Canada. Can. J. Plant Sci. 89:405-410.

14. Grunwald, N., Kitner, M., McDonald, V., and Goss, E. M. 2008. Susceptibility in Viburnum to Phytophthora ramorum. Plant Dis. 92:210214.

15. Jackson, E. W., Obert, D. E., Menz, M., Hu, G., Avant, J. B., Chong, J., and Bonman, J. M. 2007. Characterization and mapping oat crown rust resistance using three assessment methods. Phytopathology 97:10631070.

16. Jung, G. P., Skroch, P. W., Coyne, D. P., Nienhuis, J., Ariyarathe, H., Kaeppler, S., and Bassett, M. 1997. Molecular marker-based genetic analysis of tepary-bean-derived common bacterial blight resistance in different developmental stages of common bean. J. Am. Hortic. Sci. 122:329-337.

17. Kelly, J. D., Gepts, P., Miklas, P. N., and Coyne, D. P. 2003. Tagging and mapping of genes and QTL and molecular-marker assisted selection for traits of economic importance in bean and cowpea. Field Crops Res. 82:135-154.

18. Kokko, E. G., Conner, R. L., Lee, B., Kuzyk, A. D., and Kozub, G. C. 2000. Quantification of common root rot symptoms in resistant and susceptible barley by image analysis. Can. J. Plant Pathol. 22:38-43.

19. Lamari, L. 2002. ASSESS: Image Analysis Software for Plant Disease Quantification. American Phytopathological Society Press, St. Paul, MN.

20. Liu, S., Yu, K., and Park, S. J. 2008. Development of STS markers and QTL validation for common bacterial blight resistance in common bean. Plant Breed. 127:62-68.

21. Martin, D. P., and Rybicki, E. P. 1998. Microcomputer-based quantification maize streak symptoms in Zea mays. Phytopathology 88:422-427.

22. Martin, D. P., Willment, J. A., and Rybicki, E. P. 1999. Evaluation of maize streak virus pathogenicity in differentially resistant Zea mays genotypes. Phytopathology 89:695-700.

23. Michaels, T. E., Smith, T. H., Larsen, J., Beattie, A. D., and Pauls, K. P. 2006. 'OAC Rex' common bean. Can. J. Plant Sci. 86:733-736.

24. Miklas, P. N., Coyne, D. P., Grafton, K. F., Mutlu, N., Reiser, J., Lindgren, D. T., and Singh, S. P. 2003. A major QTL for common bacterial blight resistance derives from the common bean great northern landrace cultivar Montana No. 5. Euphytica 131:137-146.

25. Miklas, P. N., Johnson, E., Stone, V., Beaver, J. S., Montoya, C., and Zapata, M. 1996. Selective mapping of QTL conditioning disease resistance in common bean. Crop Sci. 36:1344-1351.

26. Miklas, P. N., Kelly, J. D., Beebe, S. E., and Blair, M. W. 2006. Common bean breeding for resistance against biotic and abiotic stresses: From classical to MAS breeding. Euphytica 147:105-131.

27. Miklas, P. N., Smith, J. R., Riley, R., Grafton, K. F., Singh, S. P., Jung, G., and Coyne, D. P. 2000. Marker-assisted breeding for pyramided resistance to common bacterial blight in common bean. Annu. Rep. Bean Improv. Coop. 43:39-40.

28. Mkandawire, A. B. C., Mabagala, R. B., Guzman, P., Gepts, P., and Gilbertson, R. L. 2004. Genetic diversity and pathogenic variation of common blight bacteria (Xanthomonas campestris pv. phaseoli and $X$. campestris pv. phaseoli var. fuscans) suggests pathogen co-evolution with the common bean. Phytopathology 94:593-603.

29. Mutlu, N., Miklas, P., Reiser, J., and Coyne, D. 2005. Backcross breeding for improved resistance to common bacterial blight in pinto bean (Phaseolus vulgaris L). Plant Breed. 124:282-287.
30. Mutlu, N., Vidaver, A. K., Coyne, D. P., Steadman, J. R., Lambrecht, P. A., and Reiser, J. 2008. Differential pathogenicity of Xanthomonas campestris pv. phaseoli and X. fuscans subsp. fuscans strains on bean genotypes with common blight resistance. Plant Dis. 92:546-554.

31. Newton, A. C. 1989. Measuring the sterol content of barley leaves infected with powdery mildew as a means of assessing partial resistance to Erysiphe graminis f. sp. hordei. Plant Pathol. 38:534-540.

32. Nutter, F.W., Jr., Esker, P. D., and Coelho Netto, R. A. 2006. Disease assessment concepts in plant pathology. Eur. J. Plant Pathol. 115:95103.

33. O'Boyle, P. D., Kelly, J. D., and Kirk, W. W. 2007. Use of marker assisted selection to breed for resistance to common bacterial blight in common bean. J. Am. Soc. Hortic. Sci. 132:381-386

34. Olmstead, J. W., and Lang, G. A. 2001. Assessment of powdery mildew infection of sweet cherry leaves by digital image analysis. Hortic. Sci. 36:107-111.

35. Park, S. O., Coyne, D. P., Mutlu, N., Jung, G., and Steadman, J. R. 1999. Confirmation of molecular markers and flower color associated with QTL for resistance to common bacterial blight in common beans. J. Am. Soc. Hortic. Sci. 124:519-526.

36. Park, S. J., and Dhanvantari, B. N. 1987. Transfer of common blight (Xanthomonas campestris pv. phaseoli) resistance from Phaseolus coccineus Lam. to $P$. vulgaris L. through interspecific hybridization. Can. J. Plant Sci. 67:685-695.

37. Pedraza, F., Gallego, G., Beebe, S., and Tohme, J. 1997. Marcadores SCAR y RAPD para la resitencia a la bacteriosis comun (CBB). Pages 130-134 In: Taller de mejoramiento de frijol para el Siglo XXI: Bases para una estrategia para America Latina. S. P. Singh, and O. Voysest, eds. CIAT, Cali.

38. Poland J. A., and Nelson, R. J. 2011. In the eye of the beholder: The effect of rater variability and different rating scales on QTL mapping. Phytopathology 101:290-298.

39. Price, T. V., Gross, R., Ho Wey, J., and Osborne, C. F. 1993. A comparison of visual and digital image-processing methods in quantifying the severity of coffee leaf rust (Hemileia vastatrix). Aust. J. Exp. Agric. 33:97-101

40. Saettler, A. W. 1991. Common bacterial blight. Pages 29-30 in: Compendium of Bean Diseases. R. Hall, ed. American Phytopathological Society Press, St. Paul, MN.

41. Silva, L. O., Singh, S. P., and Pastor-Corrales, M. A. 1989. Inheritance of resistance to bacterial blight in common bean. Theor. Appl. Genet. 78:619-624.

42. Singh, S. P., and Munoz, C. G. 1999. Resistance to common bacterial blight among Phaseolus species and common bean improvement. Crop. Sci. 39:80-89.

43. St. Clair, D. A. 2010. Quantitative disease resistance and quantitative resistance loci in breeding. Annu. Rev. Phytopathol. 48:247-268.

44. Steel, R. G. D., Torrie, J. H., and Dickey, D. A. 1997. Analysis of variance II: Multiway classifications. Pages 204-252 in: Principles and Procedures of Statistics: A Biometrical Approach, 3rd ed. R. G. D. Steel, J. H. Torrie, and D. A. Dickey, eds. WCB/McGraw-Hill, New York.

45. Tar'an, B., Michaels, T. E., and Pauls, K. P. 2001. Mapping genetic factors effecting the reaction to Xanthomonas axonopodis pv. phaseoli in Phaseolus vulgaris L. under field conditions. Genome 44:1046-1056.

46. Thomas, C. V., and Waines, J. G. 1984. Fertile backcross and allotetraploid plants from crosses between tepary beans and common beans. J. Hered. 75:93-98.

47. Tjosvold, S. A., and Chambers, D. L. 2006. Correlation of lesion size with percent lesion coverage on camellia and rhododendron leaves inoculated with Phytophthora ramorum. (Abstr.) Phytopathology 96:S114.

48. Todd, L. A., and Kommedahl, T. 1994. Image analysis and visual estimates for evaluating disease reactions of corn to Fusarium stalk rot. Plant Dis. 78:876-878.

49. Tucker, C. C., and Chakraborty, S. 1997. Quantitative assessment of lesion characteristics and disease severity using digital image processing. J. Phytopathol.145:273-278.

50. Vandemark, G. J., Fourie, D., Larsen, R. C., and Miklas, P. N. 2009. Interactions between QTL SAP6 and SU91 on resistance to common bacterial blight in red kidney bean and pinto bean populations. Euphytica 170:371-381.

51. Vandemark, G. J., Fourie, D., and Miklas, P. N. 2008. Genotyping with real-time PCR reveals recessive epistasis between independent QTL conferring resistance to common bacterial blight in dry bean. Theor. Appl. Genet. 117:513-522

52. Vicent, A., Armengol, J., and Garcia-Jimenez, J. 2007. Rain fastness and persistence of fungicides for control of Alternaria brown spot of citrus. Plant Dis. 91:393-399.

53. Yu, K., Park, S. J., and Poysa, V. 1999. Abundance and variation of microsatellite DNA sequences in beans (Phaseolus and Vigna). Genome 42:27-34. 
54. Yu, K., Park, S. J., and Poysa, V. 2000. Marker-assisted selection of common beans for resistance to common bacterial blight: Efficacy and economics. Plant Breed. 119:411-415.

55. Yu, K., Park, S. J., Zhang, B., Haffner, M., and Poysa, V. 2004. An SSR marker in the nitrate reductase gene of common bean is tightly linked to a major gene conferring resistance to common bacterial blight. Euphytica 138:89-95.

56. Yu, Z. H., Stall, R. E., and Vallejos, C. E. 1998. Detection of genes for resistance to common bacterial blight of beans. Crop Sci. 38:1290-1296.

57. Zapata, M. 2006. Proposed of a uniform screening procedure for the evaluation of variability of Xanthomonas axonopodis pv. phaseoli and resistance on leaves of Phaseolus vulgaris under greenhouse conditions. Annu. Rep. Bean Improv. Coop. 49:213-214.

58. Zapata, M., Beaver, J. S., and Porch T. G. 2010. Dominant gene for common bean resistance to common bacterial blight caused by Xanthomonas axonopodis pv. phaseoli. Euphytica 179:373-382. 